NASA Technical Memorandum 103113

\title{
Simplified Design Procedures for Fiber Composite Structural Components/Joints
}

P.L.N. Murthy and C.C. Chamis

Lewis Research Center

Cleveland, Ohio

Prepared for the

Indo-U.S. Workshop on Composite Materials for Aerospace Applications sponsored by the Indian Institute of Science

Bangalore, India, July 23-27, 1990 



\title{
SIMPLIFIED DESIGN PROCEDURES FOR FIBER COMPOSITE STRUCTURAL COMPONENTS/JOINTS
}

\author{
P.L.N. MURTHY AND C.C. CHAMIS' \\ National Aeronautics and Space Administration, Lewis Research Center, \\ Cleveland, Ohio 44135
}

\begin{abstract}
SUMMARY
Simplified step-by-step design procedures are summarized, which are suitable for the preliminary design of composite structural components such as panels (laminates) and composite built-up structures (box beams). Similar procedures are also summarized for the preliminary design of composite bolted and adhesively bonded joints. The summary is presented in terms of sample design cases complemented with typical results. Guidelines are provided which can be used in the design selection process of composite structural components/joints. Also, procedures to account for cyclic loads, hygrothermal effects and lamination residual stresses are included.
\end{abstract}

\section{INTRODUCTION}

The fiber composites technology is rapidly maturing to the extent that these composites have been used as prime materials in advanced aerospace structures where performance is important. As the cost becomes competitive with conventional materials, fiber composites become attractive alternatives for use in more traditional applications where cost rather than performance is the major design driver. Fiber composite structures, like other structures, are assemblages of typical structural components. A typical fiber composite structural component is a panel or plate subjected to in-plane loads.

The design of fiber composite structural components requires analysis methods and procedures which relate the structural response of the component to the specified loading and environmental conditions. The structural response is eventually compared to given design criteria for strength, displacement, buckling, vibration frequencies, etc., in order to ascertain that the component will perform satisfactorily. Though there are several recent books on composite mechanics available [1-6], none covers design procedures for fiber composite structural components in any detail.

Another important aspect in composite structural design is joints. It is generally considered that joints determine the structural integrity. Composite joints have been extensively investigated in recent years. Results of these investigations are reported, in part, in symposium proceedings $[7,8]$. Helpful recommendations for design practice for select composite joints are included in Reference 9. Analysis methods for detailed stress calculations are described in Reference 10. Though relevant information for designs may be collected from the above cited reference, step-by-step sample cases are not available. Recent

\footnotetext{
*Aerospace Structure Engineer, Structures Division

†Senior Aerospace Scientist, Structures Division
} 
research at NASA Lewis Research Center has focused on developing simplified design procedures for (1) composite panels [11]; and (2) composite box beams [12], composite bolted joints [13], and composite adhesively bonded joints

[14]. These references describe step-by-step design procedures that are suitable for preliminary designs.

The objective of this paper is to provide (1) summaries of these design procedures with typical results in order to demonstrate what can be done and how to get started, and (2) a brief outline on how to account for hygrothermal effects, cyclic loads and lamination residual stress in the design procedure. The level of detail and results in the summaries differ depending on what the authors considered adequate to illustrate that procedure. The complete details, results, and relevant references are described in References 11 to 14.

\section{COMPOSITE PANELS SUBJECTED TO COMBINED IN-PLANE LOADS}

Composite panels (membranes) are structural components which generally have a rectangular shape. They can be used individually (Fig. 1) or as members of bulit-up structural components as described in the next section. They usually are designed to support combined in-plane loading conditions (Fig. 1). The loading conditions can include: (1) static loads, (2) static with superimposed cyclic loads, (3) hot-wet (hygrothermal) environmental effects, and (4) lamination residual stresses. A sample design for only static loads is presented, and the procedures used for analyzing loading conditions (2) to (4) are briefly outlined. Furthermore, only the steps to size the laminate for strength and buckling are summarized. The details for the complete design are described in Reference 11.

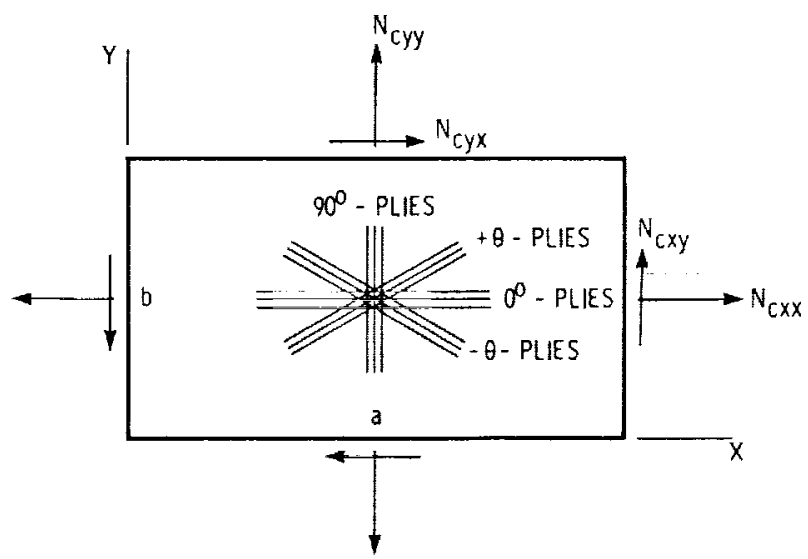

Figure 1. - Schematic of angleplied fiber composite panel subjected to combined in-plane loads. 
Sample Design - Size Panel From Strength

Structural component: Rectangular panel, 15 by $10 \mathrm{in}$.

Specified loads:

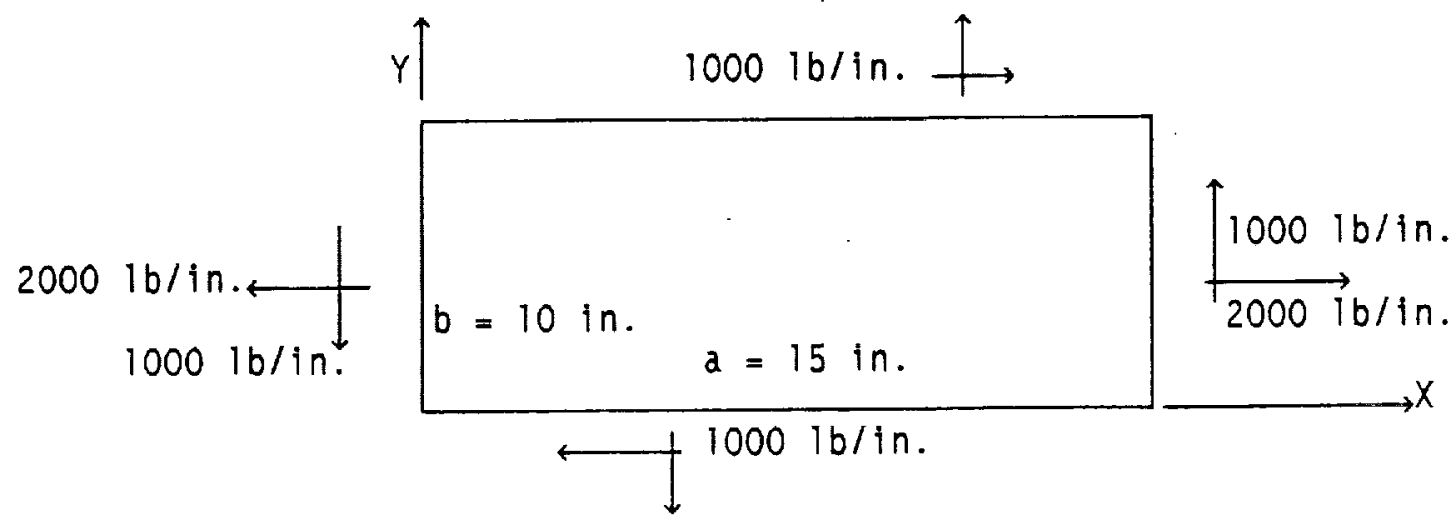

Displacement limits: $\quad 0.5$ percent of edge dimensions and $1^{\circ}$-shearing angle

Safety factor: $\quad 2.0$ on specified load

Composite system: Graphite fiber/epoxy matrix at 0.6 fiber volume ratio (FVR)

Design procedure: $\quad$ Rectangular panel designed not to exceed displacement limits, or ply strengths, or buckle at design load. specified-load ply stresses may be used instead of design load ply stresses to compute matrix-controlled ply strength margins when the fiber-controlled stress margins are relatively large.

Step 1: Design Variables

Number of plies, ply orientations, and ply stacking sequence.

\section{Step 2: Design Loads}

Safety factors times specified loads:

$$
\begin{aligned}
& N_{\text {cxx }}=2 \times 2000 \mathrm{lb} / \mathrm{in} .=4000 \mathrm{lb} / \mathrm{in} . \\
& N_{\text {cyy }}=2 \times 1000 \mathrm{lb} / \mathrm{in} .=2000 \mathrm{lb} / \mathrm{in} . \\
& N_{\text {cxy }}=2 \times 1000 \mathrm{lb} / \mathrm{in} .=2000 \mathrm{lb} / \mathrm{in} .
\end{aligned}
$$

Step 3:

Obtain composite material properties (ply and angleply) for AS/E, from Table I. The ply off axis (angleply) properties can be derived from the unidirectional ply properties using coordinate transformation. 


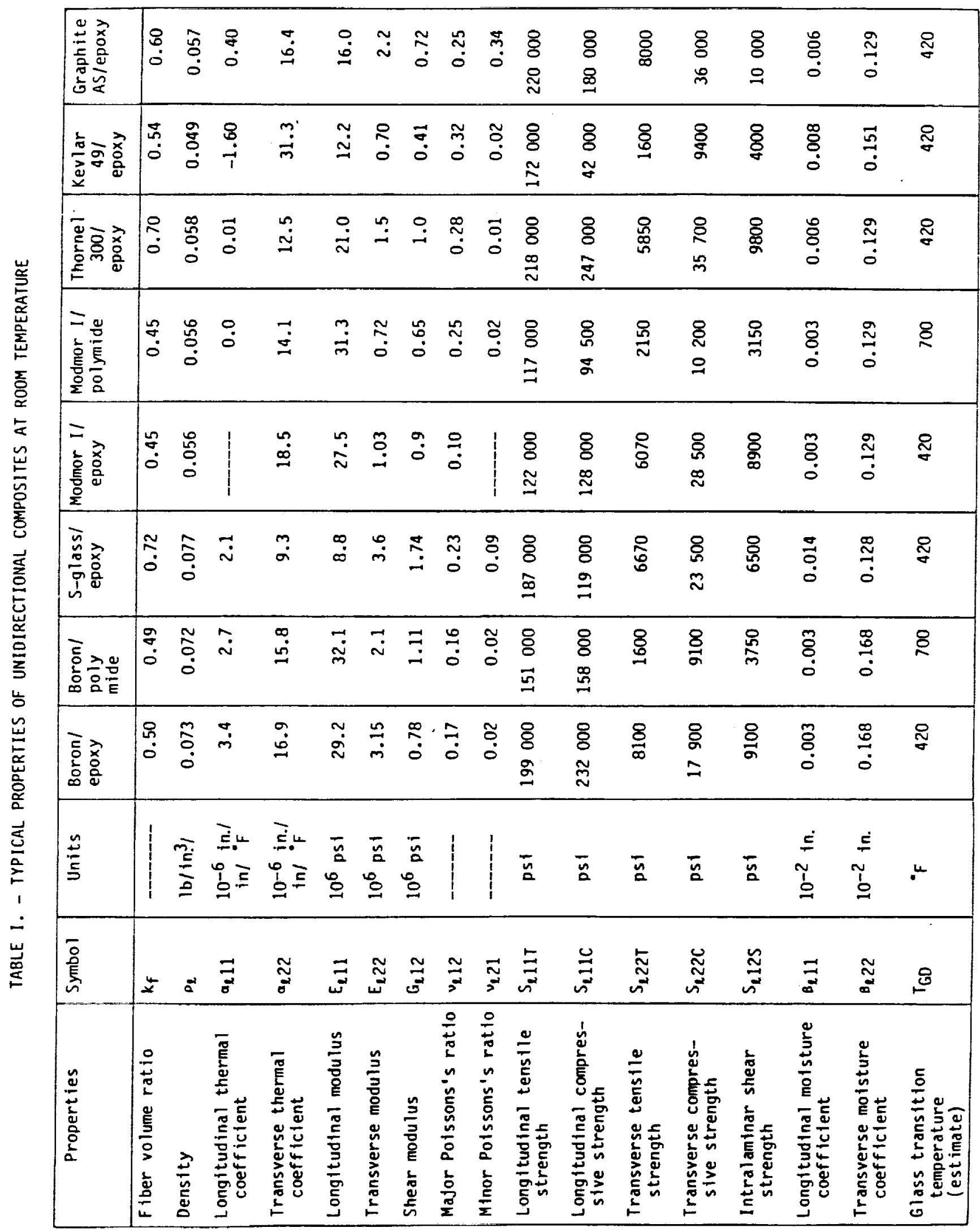


Step 4: Select Laminate Configuration

Number of $0^{\circ} \mathrm{plies}=$ Design load $\left(\mathrm{N}_{\mathrm{Cxx}}\right) /\left[\right.$ longitudinal tensile strength $\left(S_{\ell 11 T}\right.$ $=220000 \mathrm{psi}) \times$ ply thickness $\left.\left(t_{\ell}=0.005 \mathrm{in.}\right)\right]$

$$
N_{\ell O}=\frac{N_{c x x}}{S_{\ell 11 T_{l}^{t}}}=\frac{4000 \mathrm{lb} / \mathrm{in} .}{220000 \mathrm{lb} / \mathrm{sq} \mathrm{in.} \times 0.005 \mathrm{in} .}=3.64 \sim 4
$$

Use $N_{\ell O}=8$ (double because of the combined loading).

Number of $90^{\circ}$ plies = Design load $\left(N_{\text {cyy }}\right) /[$ longitudinal tensile strength $\left(S_{\ell 11 T}\right) \times$ ply thickness $\left.\left(t_{\ell}\right)\right]$

$$
N_{\ell 90}=\frac{N_{c y y}}{S_{\ell 11 T_{\ell}}}=\frac{2000 \mathrm{lb} / \mathrm{in} .}{220000 \mathrm{lb} / \mathrm{sq} \mathrm{in.} \times 0.005 \mathrm{in} .}=1.82 \sim 2
$$

Use $N_{\ell 90}=4$ (double because of the combined loading).

Number of $\pm 45^{\circ}$ plies $=$ Design load $\left(N_{C x y}\right) \times$ one-half the ratio of the ply longitudinal ( $E_{\ell 1} 1=18.5 \mathrm{mpsi}$ ) to $\pm 45^{\circ}$-composite shear modulus

$\left(\mathrm{G}_{\theta 12}=5.8 \mathrm{mpsi}\right) /\left[\right.$ longitudinal compressive strength $\left(\mathrm{S}_{\ell} 11 \mathrm{C}=180000 \mathrm{psi}\right) \times$ ply thickness $\left(t_{\ell}=0.005\right.$ in.) ]

$$
N_{\ell \pm 45}=\frac{N_{c x y} \times(1 / 2)\left(E_{\ell 11} / G_{\theta 12}\right)}{S_{\ell 11 C^{t}}}=\frac{20001 \mathrm{~b} / \mathrm{in} .(1 / 2)(18.5 / 5.8)}{180000 \mathrm{lb} / \mathrm{sq} \text { in. } \times 0.005 \mathrm{in} .}=3.5 \sim 4
$$

Use $\mathrm{N}_{\ell \pm 45}=8$ (double because of the combined loading). Therefore, the laminate is 20 plies $\left(8\right.$ at $0^{\circ}, 8$ at $\pm 45^{\circ}$, and 4 at $\left.90^{\circ}\right)$. The laminate thickness $\left(t_{\ell}\right)$ is $20 \times 0.005 \mathrm{in} .=0.10 \mathrm{in}$.

And the required laminate configuration (using the conventional designation) is:

$$
[ \pm 45 / 0 / 90 / 0] 25
$$

Notes:

(1) The laminate was initially sized using fiber-controlled properties. The number of plies in each orientation was doubled in order to approximately account for the combined loading stresses which are resisted by matrixcontrolled properties.

(2) The $\pm 45^{\circ}$ plies were placed on the outside for increased shear buckling resistance.

(3) The longitudinal compression strength was selected for determining the number of $\pm 45^{\circ}$ plies because this is less than the longitudinal tensile strength ( 180000 ps 1 ( 220000 psi, Table I).

(4) The force deformation relationships which are needed to check for laminate displacements are determined from classical laminate theory or as described in Reference 1.

(5) The ply stresses and the respective margins are also determined from laminate theory.

\section{Checks for Shear Buckling}

The design of thin panels is generaliy governed by stability consideration when they are subjected to either compressive or in-plane shear loads. Since the 
panel is subjected to tensile and shear loads, the panel needs to be checked only for shear buckling. Shear buckling is estimated by using the following approximate equation if the tensile stresses ( $\sigma_{C x x}$ and $\sigma_{c y y}$ ) are neglected

$$
\sigma_{c x y}^{(c r)}=\frac{7 \pi^{2} t_{c}^{2} E}{12 b^{2}\left(1-v_{c x y}{ }^{{ }^{2} c y x}{ }\right)}(1 \leq a / b \leq 2) \quad E=\sqrt[3]{4 E_{c x x} E_{c y y} G_{c x y}}
$$

For our laminate, the values are [1].

$$
\begin{aligned}
& v_{\text {Cxy }}=0.33 \\
& v_{\text {Cyx }}=0.22 \\
& E_{\text {cxx }}=9.6 \mathrm{mps} i \\
& E_{\text {cyy }}=6.5 \mathrm{mps} i \\
& G_{\text {cxy }}=2.3 \mathrm{mps} i
\end{aligned}
$$

Using these moduli values in the equation for $E$, we calculate:

$$
E=\sqrt[3]{4 \times 9.6 \times 6.5 \times 2.3} \mathrm{mpsi}=8.31 \mathrm{mps} i
$$

Using this value for $E$, the values for $v_{c x y}$ and $v_{c y x}, b=10 i n$. and $t_{c}=0.1 \mathrm{in}$. in the equation for $\sigma_{c x y}^{(c r)}$, we calculate:

$$
\sigma_{c x y}^{(c r)}=\frac{7 \pi^{2}(0.1)^{2} \mathrm{in.}^{2} \times 8.31 \times 10^{6} \mathrm{lb}}{12 \times 10 \mathrm{in} . \times 10 \mathrm{in} . \times(1-0.33 \times 0.2) \mathrm{in}^{2}}=5117 \mathrm{psi}
$$

Check: $\sigma_{\text {cxy }}^{(c r)} \geq \sigma_{c x y}$ (design)

5117 psi< 20000 psi

$$
\text { MOS }=\frac{5117}{20000}-1.0=-0.74
$$

where MOS is the margin of safety. A positive value indicates a safe design and a negative value implies that failure is imminent. Therefore, the shear buckling stress needs to be checked in combination with the two normal ( $\sigma_{\mathrm{Cxx}}$ and $\left.\sigma_{C y y}\right)$ tensile stresses.

An estimate of buckling resistance may be obtained from the approximate interaction equation given by

$$
\frac{\sigma_{c x x}}{\sigma_{c x x}^{(c r)}}+\frac{\sigma_{c y y}}{\sigma_{c y y}^{(c r)}}-\left[\frac{\sigma_{c x y}}{\sigma_{c x y}^{(c r)}}\right]^{2}+1.0 \geq 0
$$

where $\sigma_{c x x}, \sigma_{c y y}$, and $\sigma_{c x y}$ are the laminate stresses at design load. The buckling stresses $\sigma_{c x x}^{(c r)}$ and $\sigma_{c y y}^{(c r)}$ are roughly approximated from 


$$
\sigma_{c y y}^{(c r)}=\sigma_{c x x}^{(c r)} \approx \frac{\pi^{2} t_{c}^{2} E}{12 b^{2}\left(1-v_{c x y}{ }_{c y x}\right)}\left(\frac{a}{b}+\frac{b}{a}\right)^{2}
$$

where $E$ and $v_{c}$ are the same as before. Using respective values for the moduli, Poisson's ratios $b, a$, and $t_{c}$, we calculate

$$
\begin{gathered}
\sigma_{c y y}^{(c r)}=\sigma_{c x x}^{(c r)} \approx \frac{\pi^{2} \times(0.1)^{2} \times 8310000}{12 \times 10 \times 10 \times(1-0.33 \times 0.22)}\left(\frac{15}{10}+\frac{10}{15}\right)^{2} p s i \\
\sigma_{c y y}^{(c r)}=\sigma_{c x x}^{(c r)} \approx 3433 p s i
\end{gathered}
$$

Substituting the following:

$$
\begin{aligned}
& \sigma_{c x x}=40000 \text { psi; } \sigma_{c x x}^{(c r)}=3433 p s i \\
& \sigma_{c y y}=20000 \text { psi; } \sigma_{c y y}^{(c r)}=3433 p s i \\
& \sigma_{c x y}=20000 \text { psi; } \sigma_{c x y}^{(c r)}=5117 p s i
\end{aligned}
$$

in the interaction equation, we calculate

$$
\begin{gathered}
\frac{40000}{3433}+\frac{20000}{3433}-\left(\frac{20000}{5117}\right)^{2}+1.0>0 \\
11.65+5.83-15.28+1.0=3.2>0 \quad 0 . k .
\end{gathered}
$$

Therefore, based on the estimate obtained using the interaction equation the panel should not buckle at the design shear stress, provided that all three loads ( $N_{c x x}, N_{c y y}$, and $N_{c x y}$ ) are applied proportionally and simultaneously. This can also be stated as: $N_{c y y}$ and $N_{c x y}$ are proportional to $N_{c x x}$. It is important to observe the dramatic positive effect of the normal tensile stresses on the shear buckling strength. A more accurate estimate may be obtained by performing finite element analysis. The results of the final design are summarized below. The margins are given on the design loads unless otherwise noted. The details of the calculations for the margins on the displacements and ply stresses are given in Reference 11.

(1) Laminate configuration $[ \pm 45 / 0 / 90 / 0]_{25}$

(2) Margins of safety on displacement design requirements

\begin{tabular}{|c|c|}
\hline Displacement & Margin \\
\hline$(u / a)$ & 0.43 \\
$(v / b)$ & 1.94 \\
$\Delta \theta$ & 0.33 \\
\hline
\end{tabular}


(3) Margins of safety on ply stress limits

\begin{tabular}{|r|c|c|c|}
\hline \multirow{2}{*}{ Ply } & \multicolumn{3}{|l|}{ Margins for stress } \\
\cline { 2 - 4 } & $\sigma_{\ell 11}$ & $\sigma_{\ell 22}$ & $\sigma_{\ell 12}$ \\
\hline 0 & 2.77 & 0.61 & 1.30 \\
45 & 0.79 & $\infty$ & $\infty$ \\
-45 & 4.43 & 0.27 & $\infty$ \\
90 & 6.00 & 0.12 & 1.30 \\
\hline
\end{tabular}

Note: $\sigma_{\ell 22}$ and $\sigma_{\ell 12}$ in the $45^{\circ}$ ply as well as $\sigma_{\ell 12}$ in $-45^{\circ}$ ply are quite insignificant making the MOS very large [11].

(4) Margin of safety on shear buckling stress

\begin{tabular}{|c|c|c|c|}
\hline \multicolumn{2}{|c|}{ Case (stress in psi) } & \multirow{2}{*}{$\begin{array}{c}\text { Margin } \\
\text { for } \\
\sigma_{\text {cxy }}^{(c r)}\end{array}$} \\
\hline$\sigma_{\text {cxx }}$ & $\sigma_{\text {cyy }}$ & $\sigma_{\text {cxy }}$ & $\sigma_{\text {cy }}$ \\
\hline 0 & 0 & 20000 & -0.74 \\
40000 & 20000 & 20000 & 3.2 \\
\hline
\end{tabular}

\section{CANTILEVER BOX BEAMS SUBJECTED TO FREE-END LOADS}

An important class of structural components that can readily be made using fiber composites are box beams. Box beams are generally used to span long distances and to resist combined loads. Box beams are the main structural components in aircraft wings. They are made using thin flat/curved laminates, are designed to resist the loads primarily through membrane action and are designed to have constant or tapered cross sections. In addition, the laminate thickness for the covers and sides can be different and varied along the span. In what follows, the step-by-step procedures that were described above for the preliminary design of composite panels subjected to combined loadings have been extended for the preliminary design of composite box beams.

These procedures include a collection of simple equations to expedite the various calculations performed during the preliminary design phase. They are demonstrated by applying them to a preliminary design of a tapered cantilever box beam. The box beam is subjected to combined loads at the free end. It is designed to meet strength, displacement, buckling, and frequency requirements. The various steps involved are described in detail with ample explanatory notes so that they can be used to aid in the preliminary design of built-up composite structural components in general. 
Sample Design - Size Box Beam to Meet Specified Design Requirements

It is necessary to have as complete a definition of the specific design as is possible in order to initiate the preliminary design phase. For the illustrative example described herein, this definition consists of the following.

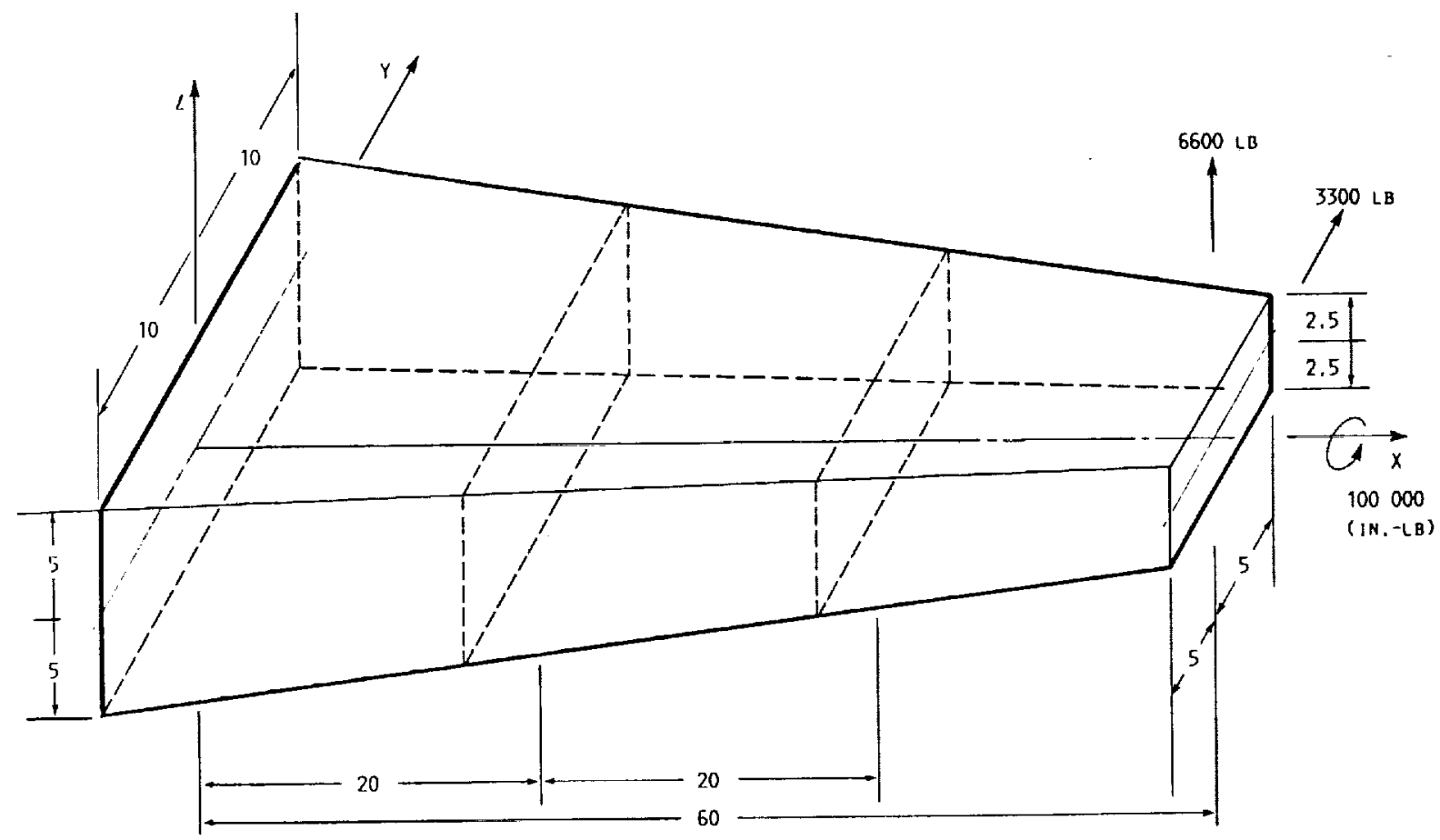

FIGURE 2. - COMPOSITE BOX BEAM GEOMEIRY AND SPECIFIED LOADING CONDITIONS (ALL DIMENSIONS IN INCHES: LOADS IN POUNDS: TWIST MOMENT IN INCH-POUNDS).

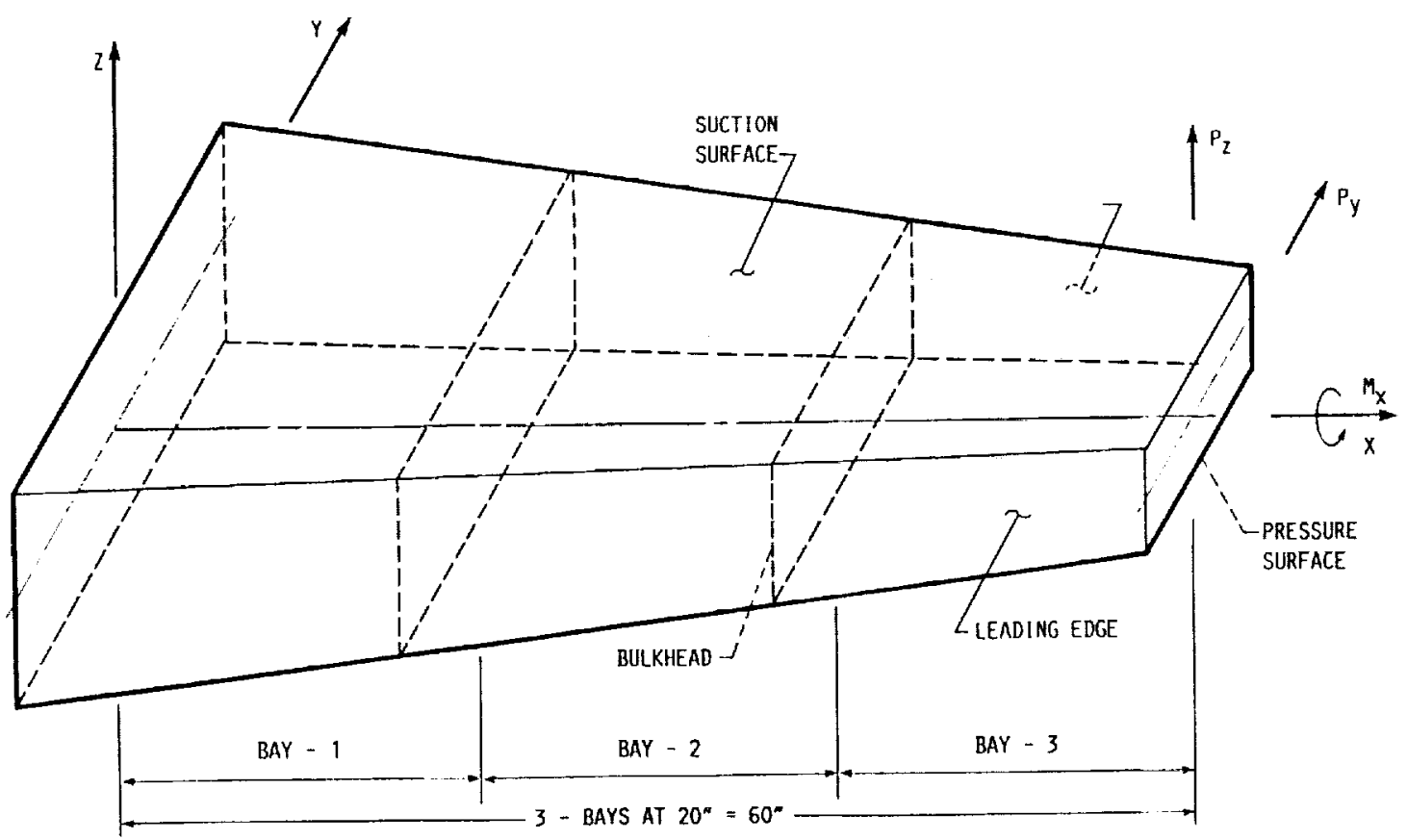

FIGURE 3. - COMPOSITE BOX BEAM SURFACE AND DESIGN LOAD NOMENCLATURE. 
(1) Structural Component:

Cantilever, three-bay box beam (schematics Figs. 2 and 3 ).

(2) Specified Loads:

Free-end static loads (Fig. 2).

6600 lb vertical; 3300 lb lateral; $100000 \mathrm{lb}$ in twist moment.

(3) Displacement Limits:

Tip displacements less than 1.5-percent of length; angle of twist less than $1^{\circ}$.

(4) Frequencies:

Flap greater than 100 cycle/sec, edge greater than 150 cycle/sec; twist greater than 450 cycle/sec.

Local panel frequencies to be greater than box beam global frequencles.

(5) Safety Factor:

2.0 times specified load.

(6) Composite System:

Graphite fiber in epoxy matrix at 0.6 fiber volume ratio.

(7) Design Procedure/Requfrements:

Box beam not to exceed displacement limits.

Laminates in various bays not to exceed ply fiber-controlled strengths at design loads or ply matrix controlled strengths at specified loads. Composite panels in each bay not to exceed combined stress buckling.

(8) General philosophy on preliminary design of composite box beams:

size covers for only the vertical load and add plies for the combined

loads (lateral and twist moment).

Size side walls for only the lateral load and add plies for the combined loads (vertical and twist moment).

Once the design is defined to the extent just outlined, we are ready to design the composite laminates for the covers and the walls of the box beam by following the step-by-step design procedure.

\section{Step 1: Identify Design Variables}

Number of plies, ply orientation and stacking sequence for the composite covers and side walls for the three different bays.

\section{Step 2: Establish Design Loads}

Safety factor times specified loads (FIg. 1):

$$
\begin{aligned}
& N_{C x x}=2 \times \text { vertical load }(6600 \mathrm{lb})=13200 \mathrm{lb} \\
& N_{C y y}=2 \times \text { lateral load }(3300 \mathrm{lb})=6600 \mathrm{lb} \\
& N_{C x x}=2 \times \text { twist moment }(100000 \mathrm{lb} \text { in. })=200000 \mathrm{lb}-\mathrm{in} .
\end{aligned}
$$

\section{Step 3:}

Obtain composite material properties ( $p l y$ and $\pm \theta$ angleply) for AS/E from Table I. 


\section{Step 4:}

Select laminate configurations for box beam covers and side walls in each of the three bays. Calculate in-plane membrane loads at the bulkhead locations (Figs. 2 and 3): These loads are calculated by dividing the moment at that section by the respective depth and width. The details are described in Reference 12. Final design results are summarized in Table II for buckling stresses and in Table III for laminate stresses.

\section{BOLTED JOINTS}

Bolted joints are designed to resist certain select failure modes during the preliminary design phase. These select failure modes are those most commonly occurring in practical applications. They include: (1) local bearing, (2) net tension, (3) wedge-type splitting, (4) shear-out, and (5) tension with shear-out. These select failure modes and the approximate equations used to quantify them are summarized in Figure 4. A sample case for bearing failure is described below. Details for other failure modes and for multibolted joints as well as relevant references are described in Reference 13.

TABLE II. - BUCKLING STRESSES

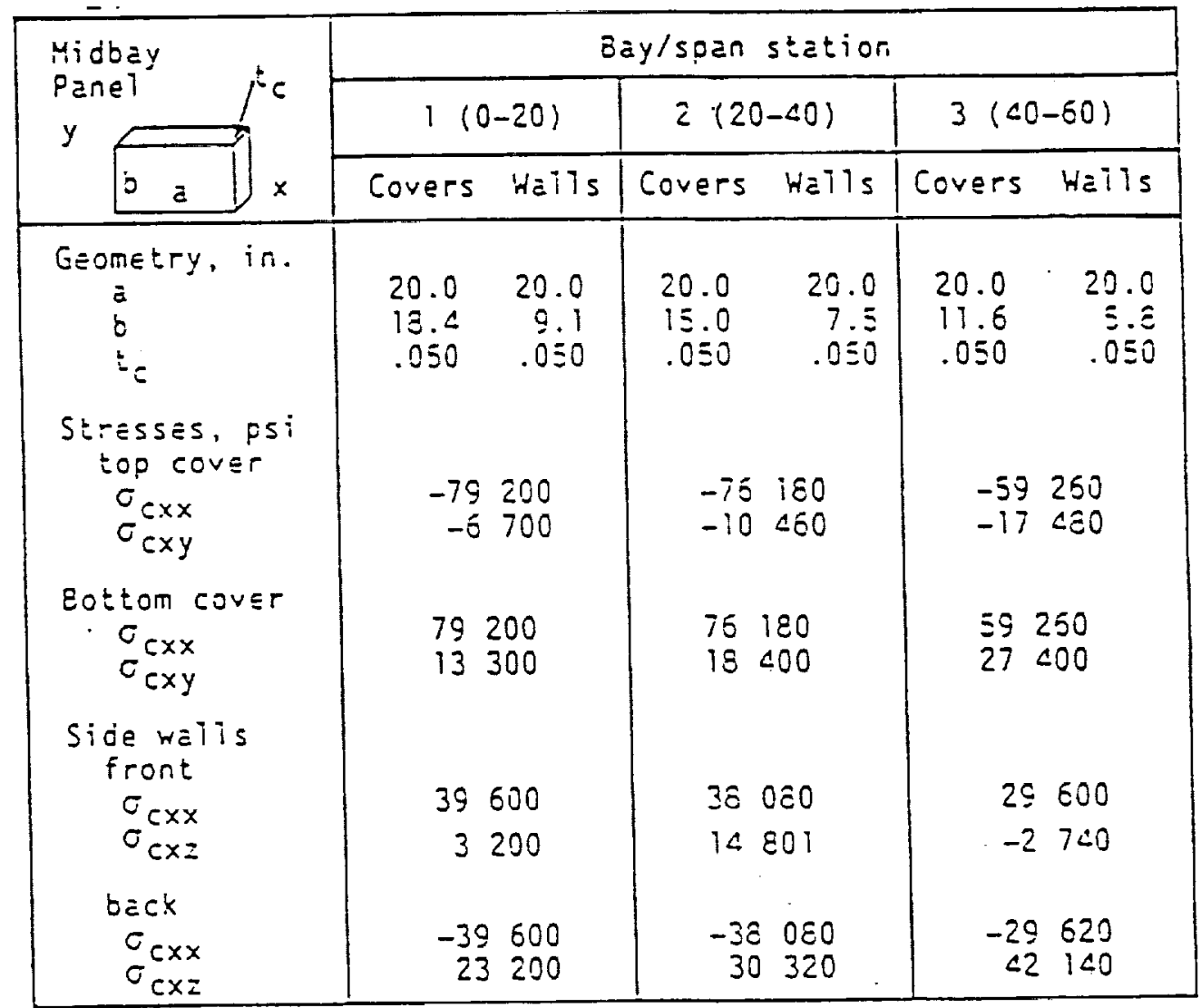


TABLE III. - FINAL DESIGY STRESSES

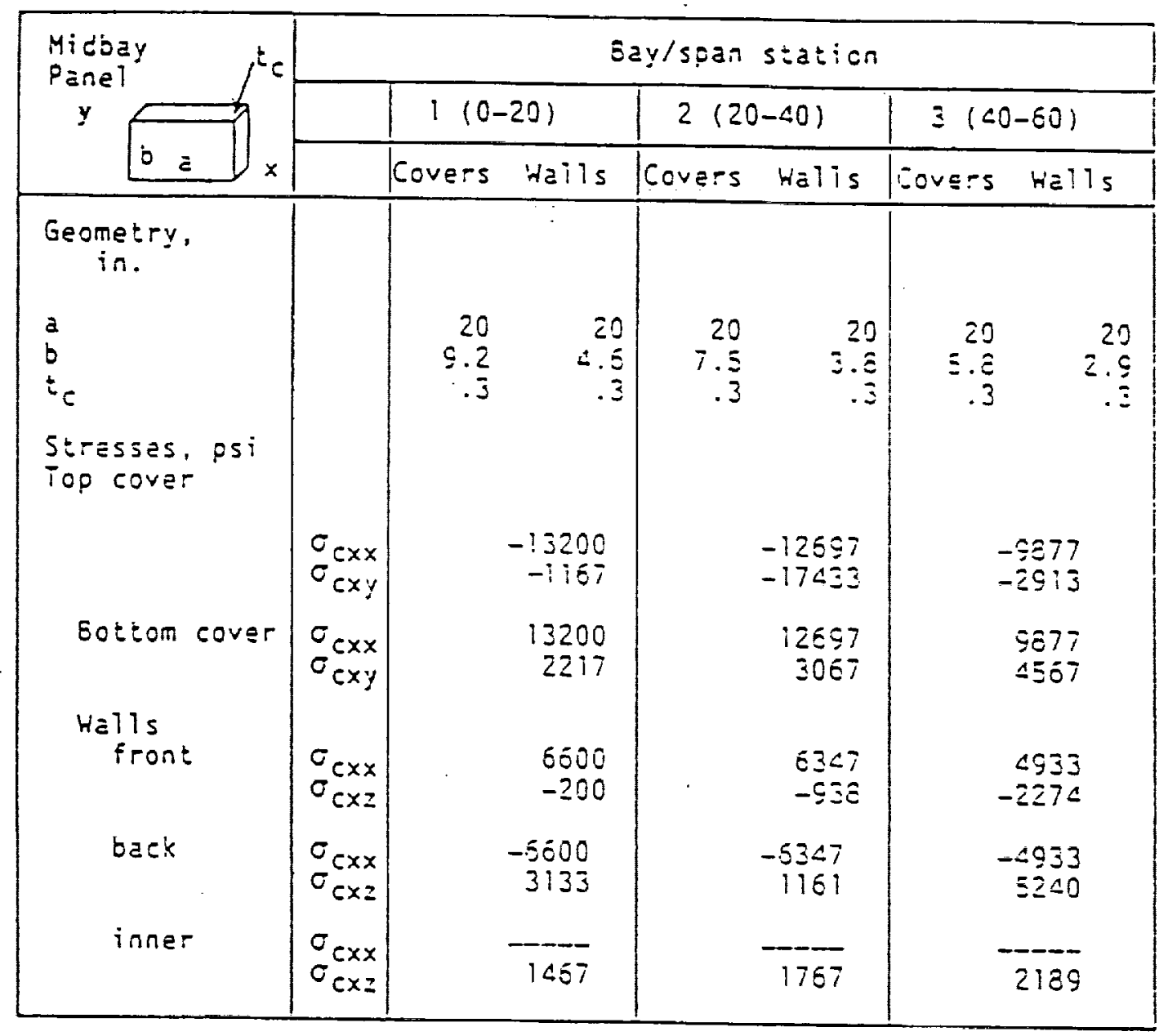

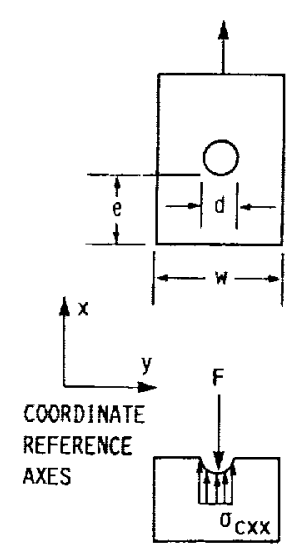

(a) LOCAL BEARING,
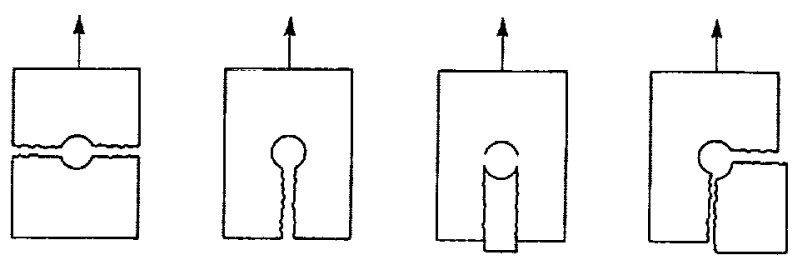

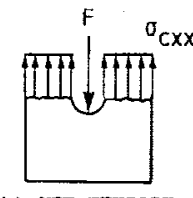

(b) NET TENSION,

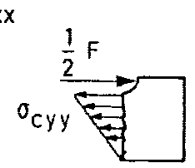

(c) WEDGE-TYPE

SPLITTING.

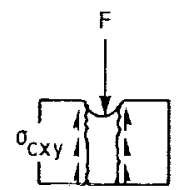

(d) SHEAR-OUT.

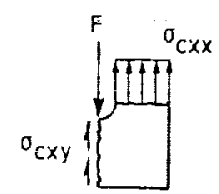

(e) TENSION WITH SHEAR-OUT

AT FRACTURE: BOLT FORCE $F=$

$d t_{c} s$ cxxc

$$
\begin{array}{rlll}
(w-d) t_{C} S_{C X X T} & \frac{1}{2}(2 e-d) I S_{C Y Y T} & 2 e t_{C} S_{C X Y S} & \frac{t c}{2}\left[(w-d) S_{C X X T}\right. \\
& \left.+2 e S_{C X Y S}\right]
\end{array}
$$

FIGURE 4. - COMPOSITE BOLTED JOINTS - FAILURE MODES ANI RESPECTIVE EQUATIONS. 
Sample Design - Size Joint for Local Bearing

Local bearing failure modes are characterized by a local laminate compressive failure caused by the bolt diameter which tends to crush the composite material. A schematic of these types of failure modes is shown in Figure 4 . The schematic which is used to derive the equation and the respective equation are also shown in Figure 4 . The requisite variables to design against this failure mode are: (1) bolt diameter $d$, (2) laminate thickness $t_{c}$, and (3) laminate compressive strength parallel to the bolt force $S_{C \times x C}$. Use of the equation (Fig. $4(a)$ ) is illustrated in the following example.

Example 1: Calculate the local average bearing stress $\left(\sigma_{C x x}\right.$ ) in a $[0 \pm 45 / 0 / 90]_{s}$ graphite fiber/epoxy matrix at 0.6 FVR laminate induced by a 1/4-in. diameter titanium bolt with a 1000 lb load. These are referred to herein as the composite bolted joint specified conditions. To perform this calculation, we first solve the equation in Figure $4(a)$ for $S_{C \times x C}$ and replace $S$ with $\sigma$

$$
\sigma_{c x x}=\frac{F}{d t_{c}}
$$

where $F$ is $1000 \mathrm{ib}, \mathrm{d}$ is $1 / 4 \mathrm{in.}$, and $t_{c}$ is $0.05 \mathrm{in}$. (10 plies at $0.005 \mathrm{in.} / \mathrm{p}(\mathrm{y})$. Using these values in the equation we obtain

$$
\sigma_{c x x}=\frac{100016}{(0.25 \times 0.05)}=80000 \text { psi }
$$

The corresponding laminate compressive strength $\left(S_{C \times x C}\right)$ from Table IV is $79700 \mathrm{psi}$. The margin of safety (MOS) against local bearing failure is

$$
\text { MOS }=\left(\frac{S_{C X X C}}{\sigma_{C X X}}\right)-1=\left(\frac{79700 p s i}{80000 p s i}\right)-1=-0.004
$$

TABLE IV. - PREDICTED FRACTURE STRESSES FOR SELECT LAMINATES ${ }^{a}$ [Graphite fiber/epoxy matrix at 0.6 FVR.]

\begin{tabular}{|l|c|c|c|}
\hline \multirow{2}{*}{$\begin{array}{c}\text { Stress } \\
\text { type }\end{array}$} & \multicolumn{3}{|c|}{ Laminate/fracture stress, ksi } \\
\cline { 2 - 4 } & {$[(0 /+45 / 0 / 90)]_{S}$} & {$\left[\left(0_{3} / \pm 80\right)\right]_{S}$} & {$[(0 /+3-10 s /-30 / 0)]_{S}$} \\
\hline$S_{C X X T}$ & 79.2 & 94.8 & 129.3 \\
$S_{C X X C}$ & 79.7 & 99.1 & 70.5 \\
$S_{\text {CyyT }}$ & 49.8 & 61.0 & 6.3 \\
$S_{\text {CyyC }}$ & 51.5 & 67.8 & 14.7 \\
$S_{\text {CxyS }}$ & 38.7 & 13.1 & 20.1 \\
$S_{\text {CZZS }}$ & 21.8 & 21.8 & 21.8 \\
\hline
\end{tabular}

apredicted using the ICAN computer code [5].

$b_{0} S$ denotes $s-g l a s s$ fiber epoxy matrix.

Notation:

$S_{c} \quad$ Laminate strength

$x, y, z$ Direction ( $x, y$ - laminate plane; $z$ - thickness

$T, C, S$ Tension, compression, shear 
Therefore, this bolted connection will barely fall in local bearing.

The results of all the fallure modes with respective margins are summarized in Table $V$.

TABLE V. - COMPOSITE BOLTED JOINT SUMMARY

[Therefore, the joint, as designed, is acceptable. It will fall locally by local bearing which is the most destrable failure mode.]

\begin{tabular}{|l|c|c|c|c|}
\hline \multirow{2}{*}{ Failure mode } & \multicolumn{2}{|c|}{ Stress, ksi } & MOS & \multirow{2}{*}{ Decision } \\
\cline { 2 - 3 } & Actual & Allowable & & \\
\hline Local bearing & 80.0 & 79.7 & -0.004 & Acceptable \\
Net tension & 26.7 & 79.2 & 1.97 & $0 . k$. \\
Wedge type splitting & 22.9 & 49.8 & 1.18 & \\
Shear-out & 10.0 & 38.7 & 2.87 & \\
Tension with shear-out & 1.0 & 3.4 & 2.42 & \\
(load per bolt kips) & 1.0 & & \\
\hline
\end{tabular}

\section{ADHESIVE BONDED JOINT}

The fundamentals and terminology associated with adhesive joints are depicted schematically in figure 5. While only two different joints are shown in this figure, the notation and geometric dimensions are similar for all the different types of joints ( $F \mid g .6$ ) to be considered in this design procedure.
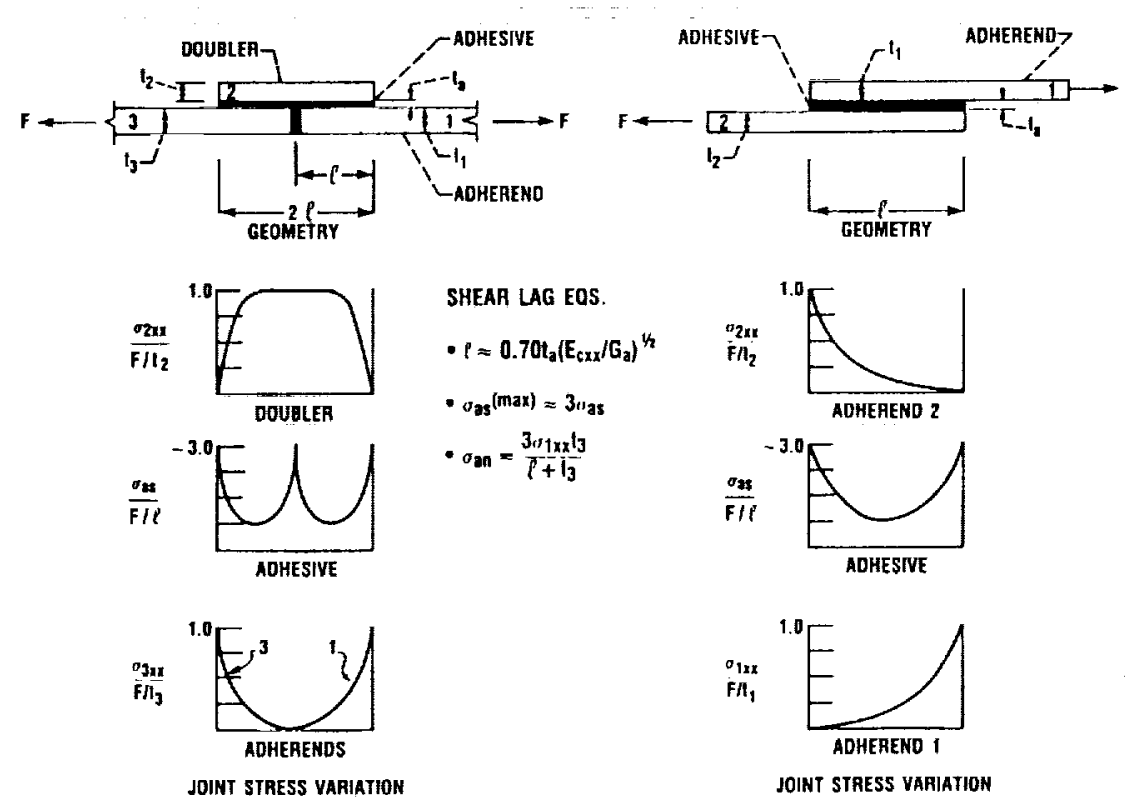

FIGURE 5. - ADHESIVE JOINT DEFINITIONS AND FUMDANENIALS. 


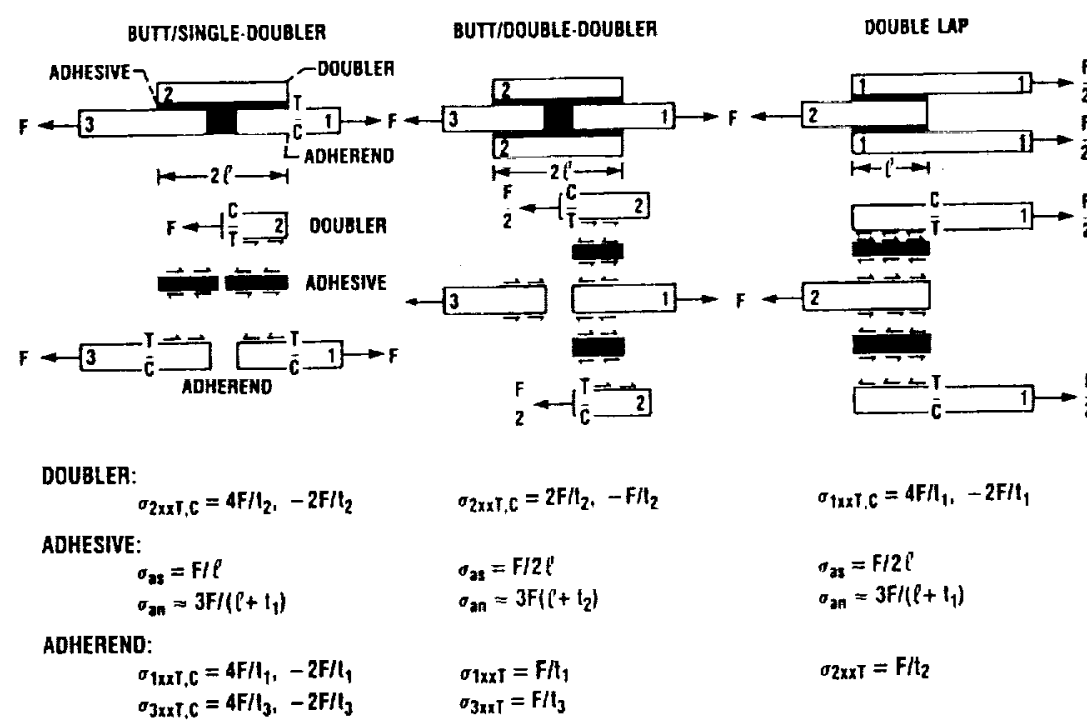

FIGURE 6. - SCHEMATICS OF COMMONLY USED ADHESIVE JOINTS (FREE BODY DIAGRAMS AND GOVERNING EQUATIONS).

The adherends and or doublers are identified by numerical subscripts while the adhesive is identified by the subscript a. All respective dimensions and stresses are identified by similar subscripts. The in-plane stress in the adherends is denoted by $\sigma_{i x x}$, for example, where $x x$ refers to the $x$-axis which is taken along the length of the joint.

The points to note in Figure 5 are: (1) the stresses transfer from one adherend to adhesive and then to the other adherend, (2) these stresses increase very rapldly from the end and are highly nonlinear, (3) the estimates are obtained from simple shear-lag theory for minimum length $\ell^{\text {min }}$, maximum shear stress in the adhesive $\sigma_{a s}^{\max }$, and maximum normal stress (peel-off stress) in the adhesive $\sigma_{a n}^{\max }$.

The general steps for designing adhesive joints are as follows:

(1) Establish joint design requirements: loads, laminates, adhesive, safety factors and other special considerations.

(2) Obtain laminate dimensions and properties for the adherends using composite mechanics. (Typical properties needed for this procedure are summarized in Tables IV and VI for three different laminates.)

(3) Obtain the properties of the adhesive. The adhesive will generally be the same as the matrix in the adherends. The specific properties needed are: (a) shear strength, and (b) peel-off strength.

(4) Select design allowables. These are either set by the design criteria or are chosen as follows: (a) a load factor on the force $F$ usually 1.5 or 2 , or (b) a safety factor of one-half of the degraded adhesive strength $S_{a}$ in step 4 above. The second alternative is preferable since the force $F$ may already contain a load factor.

(5) Select the length $\ell$ of the joint by using the following equation

$$
\ell=\frac{F}{S_{a S}}
$$

where $F$ denotes the load (tensile/compressive/shear) in the adherends per unit width and $S_{a s}$ denotes the design allowable shear stress in the adhesive. 
TABLE VI. - PREDICTED LAMINATE PROPERTIESa

[Graphite fiber/epoxy matrix at 0.6 FVR.]

\begin{tabular}{|c|c|c|c|}
\hline Property type & $(0 / \pm 45 / 0 / 90)_{S}$ & $\left(0_{3} / \pm 80\right)_{S}$ & $\left(0 /+30 / \mathrm{b}_{0} \mathrm{~s} /-30 / 0\right)_{\mathrm{S}}$ \\
\hline $\begin{array}{l}E_{c x x}, \operatorname{mps} 1 \\
E_{c y y}, \operatorname{mps} 1 \\
E_{c z z}, \operatorname{mpsi}\end{array}$ & $\begin{array}{r}10.0 \\
6.5 \\
1.4\end{array}$ & $\begin{array}{r}12.5 \\
8.3 \\
1.4\end{array}$ & $\begin{array}{r}12.8 \\
1.7 \\
1.5\end{array}$ \\
\hline $\begin{array}{l}G_{c x y}, \operatorname{mpsi} \\
G_{c y z}, \operatorname{mpsi} \\
G_{c x z}, \operatorname{mpsi}\end{array}$ & $\begin{array}{l}2.4 \\
.43 \\
.48\end{array}$ & $\begin{array}{l}7.9 \\
.43 \\
.48\end{array}$ & $\begin{array}{l}2.0 \\
.39 \\
.59\end{array}$ \\
\hline $\begin{array}{l}v_{C x y} \\
v_{C y z} \\
v_{C X z}\end{array}$ & $\begin{array}{l}.31 \\
.32 \\
.26\end{array}$ & $\begin{array}{l}.06 \\
.38 \\
.36\end{array}$ & $\begin{array}{l}.91 \\
.36 \\
.0\end{array}$ \\
\hline $\begin{array}{l}\alpha_{c x x}, \mu i n . / i n . /^{\circ} \mathrm{F} \\
\alpha_{c y y}, \mu i n . / \text { in. } /^{\circ} \mathrm{F} \\
\alpha_{c z z}, \mu i n . / \text { in. } /^{\circ} \mathrm{F}\end{array}$ & $\begin{array}{r}.41 \\
1.5 \\
20.1\end{array}$ & $\begin{array}{r}.53 \\
1.3 \\
20.1\end{array}$ & $\begin{array}{l}-.53 \\
10.1 \\
16.3\end{array}$ \\
\hline
\end{tabular}

aICAN [5].

bos denotes S-glass fiber/epoxy matrix.

(6) Check the minimum length and the maximum shear and normal stresses in the adhesive (using the shear-lag theory equations, Fig. 5).

(7) Calculate the bending stresses in the doublers and adherends using respective equations from Figure 6 .

(8) Calculate the margin of safety (MOS) for all calculated stresses. This is usually done at each step where stresses are calculated and compared to allowables using the following equation:

$$
\text { MOS }=\frac{\text { Allowable stress }}{\text { Calculated stress }}-1
$$

(9) Calculate the joint efficlency (J.E.) as follows:

$$
\text { J.E. }=\frac{\text { Jolnt force transferred }(F)}{\text { Adherend fracture load }\left(S_{(x \times} t_{1}\right)} \times 100
$$

(10) Summarize joint design.

$$
\text { Sample Design - Butt Joint With Single Doubler }
$$

As an example, the step-by-step procedure will be used to design a joint with single doubler and no environmental effects.

(1) Joint design requirements:

Loads

specified $800 \mathrm{lb} / \mathrm{in}$. static load room temperature dry conditions

Laminate

$[0 / \pm 45 / 0 / 90]_{S}$ graphite fiber/epoxy matrix at 0.6 FVR, $0.0 \overline{5}-i n$. thick 
Adhesive epoxy matrix same as in the laminate

Safety factors 1.0 on joint load; 0.5 on adhesive strengths

(2) Laminate properties: typical predicted properties for this laminate are listed in Tables IV and VI.

(3) Adhesive properties: typical properties for structural epoxies are:

$E=0.5 \mathrm{mpsi} ; G=0.18 \mathrm{mpsi} ; v=0.35 ; \alpha=30 \mathrm{ppm} /{ }^{\circ} \mathrm{F} ; \mathrm{S}_{\mathrm{an}}=15 \mathrm{ksi}$ and $S_{\text {as }}=13 \mathrm{ksi}$.

(4) Environmental effects: none since the joint will be subjected to static loads at room temperature dry conditions.

(5) Design allowables: (a) joint load: $1 \times 800 \mathrm{lb} / \mathrm{in} .=800 \mathrm{lb} / \mathrm{in}$. , (b) adhesive normal or peel-off strength: $0.5 \times 15 \mathrm{ksi}=7.5 \mathrm{ksi}$, (c) adhesive shear strength: $0.5 \times 13 \mathrm{ksi}=6.5 \mathrm{ksi}$.

(6) Joint length:

$$
\begin{gathered}
\ell=\frac{F}{S_{a s}} \\
\ell=\frac{800 \mathrm{lb} / \mathrm{in} .}{6500 \mathrm{ps}^{i}}=0.12 \mathrm{in} .
\end{gathered}
$$

and the doubler length $=2 l=0.24 \mathrm{in}$.

(7) Check joint critical conditions (equations, Fig. 1) minimum length $=0.7 t_{a}\left(E_{c x x} / G_{a}\right)^{1 / 2}$; (from Reference 4 assuming 0.99 load transfer efficiency) $t_{a}=0.005$ in., $E_{c x x}=10 \mathrm{mpsi}, G_{a}=0.18 \mathrm{mpsi}$.

$$
\begin{aligned}
& \ell^{\min }= 0.7 \times 0.005 \mathrm{in} . \times\left(\frac{10 \mathrm{mpsi}}{0.18 \mathrm{mpsi}}\right)^{1 / 2} \\
& e^{\min }=0.026 \mathrm{in} .<0.12 \mathrm{in} .
\end{aligned}
$$

Therefore, the joint length is $0.12 \mathrm{in}$. and the doubler length is $0.24 \mathrm{in}$. Use $1.0 \mathrm{in}$. since $0.24 \mathrm{in}$. is impractical for handling maximum shear stress concentration.

$$
\begin{gathered}
\ell_{a s}^{\max }=3 \times \ell_{a s} \\
\sigma_{a s}^{\max }=\frac{3 \times 800 \mathrm{ib} / \mathrm{in} .}{1 \mathrm{in} .}=2400 \text { psi } \\
2400 \text { psi<6500 psi } 0 . \mathrm{k} . \\
\operatorname{MOS}=\frac{6500 \text { psi }}{2400 \text { psi }}-1=1.71
\end{gathered}
$$

Peel-off stress (equation, Fig. 5):

$$
\sigma_{\text {an }}=\frac{3 \sigma_{1 \times x} t_{3}}{\ell+t_{3}}
$$




$$
\begin{gathered}
\sigma_{a n}=\frac{3 \times 800 \mathrm{lb} / \mathrm{in} .}{1.0+0.05 \mathrm{in} .}=2286 \mathrm{psi} \\
2286 \mathrm{psi}<7500 \mathrm{psi} \quad 0 . \mathrm{k} . \\
\text { MOS }=\frac{7500 \mathrm{psi}}{2286 \mathrm{psi}}-1.0=2.28
\end{gathered}
$$

Observations: (a) The joint length of $0.12 \mathrm{in}$. to meet design requirements was too small to be practical and was increased arbitrarily to 1 in. which is a more practical dimension. The other critical conditions are satisfied with substantial margins indicating that single doubler butt joints are not generally efficient joints; (b) the joint length as calculated by the load transfer would be relatively small; and (c) the joint length predicted by using shear lag is practically negligible indicating that the load transfer occurs in a very short distance. The bending stress for this joint are described in Reference 4. A summary of the joint design is given below.

Joint Design Summary

Doubler Laminate: $[0 / \pm 45 / 90] s$ (same as adherends)

Composite: $\quad$ graphic fiber/epoxy matrix at 0.6 FVR (same as adherends)

Adhesive: $\quad$ structural epoxy (same as epoxy in adherends)

Length: $\quad \ell=1$ in. adjusted for fabrication handling

Stresses:

\begin{tabular}{|l|c|c|c|}
\hline & $\begin{array}{c}\text { Calculated, } \\
\sigma, \\
k s i\end{array}$ & $\begin{array}{c}\text { Allowable, } \\
\text { S, } \\
\text { ksi }\end{array}$ & $\begin{array}{c}\text { Margin of } \\
\text { safety }\end{array}$ \\
\hline $\begin{array}{l}\text { Adhesive } \\
\text { Shear average }\end{array}$ & 0.8 & 6.5 & 7.12 \\
Shear maximum & 2.4 & 6.5 & 1.71 \\
Peel-off & 2.3 & 7.5 & 2.28 \\
Doubler/adherend & 64 & 79.2 & 0.24 \\
Combined-tension & 32 & 79.7 & 1.49 \\
Combined-compression & - & - & - \\
\hline
\end{tabular}

Comment: A joint without bending should be considered if the dimension and other design requirements permit it.

Sample cases for other typical joints, hygrothermal effects and relevant references are described in Reference 14.

HYGROTHERMAL EFFECTS, CYCLIC LOADS, AND LAMINATION RESIDUAL STRESSES - BRIEF OUTLINE

The sample designs described were mostly for combined static loads. However, the procedure and the governing equations used are valid when one has to take into account for hygrothermal effects, cyclic loads, and lamination residual stresses. This is accomplished by appropriately degrading the strength 
allowables used in the design. These degraded/updated strengths are used to check ply stress limits when designing the structural component/joints including hygrothermal effects, cyclic loads, and lamination residual stresses. some general guidelines are briefly described below.

\section{Hygrothermal Effects}

Hygrothermal (hot-wet) environment usually affect the matrix-controlled properties. The degraded property of the matrix due to hygrothermal affects can be estimated using the following equation $[15,16]$ when the use temperature $(T)$ and moisture pickup (M) are known:

$$
\begin{gathered}
\frac{P_{\ell H T}}{P_{\ell O}}=\left(\frac{T_{G W}-T_{G D}-T_{0}}{T_{G D}}\right)^{1 / 2} \\
T_{G W} \approx\left(0.005 M_{\ell}-0.1 M_{\ell}+1.0\right) T_{G D}
\end{gathered}
$$

where $P_{Q H T}$ is the degraded property, $T_{G W}$ is the glass transition temperature of the wet unidirectional composite, $T_{G D}$ is the glass transition temperature of the dry unidirectional composite, $T$ is the use temperature at which $P_{\ell H T}$ is required. To is the reference temperature at which $P_{l O}$ was determined and $\mathrm{M}_{\ell}$ is the moisture in the ply in percent weight.

\section{Cyclic Loads}

Cyclic loads fatigue the laminate and, therefore, the ply stress limit needs to be checked against the fatigue strength of the piy. The fatigue strength of the ply can be estimated using the following equations $[17,18]$

$$
\frac{S_{Q N}}{S_{\ell O}}=1.0-8 \log N
$$

where $S_{\ell N}$ is the fatigue strength for the specified $N$ cycles; $S_{l O}$ is the reference static strength; $B$ is a constant depending on the composite system (0.1 is a reasonable value, [10]); and $N$ is the number of cycles. Usually a safety factor (ranging from 2 to 4 ) is applied to $S_{Q N}$ to obtain $S_{2 N A}$ the strength allowable to be used in the design. This is used as the ply strength to check for the ply stress limits and to determine the margins of safety. In the presence of combined static and cyclic loads, the ply stress limit is estimated from the following equation [18]

$$
\frac{\sigma_{\ell S T}}{S_{\ell}}+\frac{\sigma_{\ell C y C}}{S_{\text {QNA }}} \leq 1.0
$$

where $\sigma_{\ell S T}$ is the ply stress $\left(\sigma_{\ell 11}, \sigma_{\ell 22}\right.$, and $\left.\sigma_{\ell 12}\right)$ due to design static load; $\sigma_{\ell c y c}$ is the corresponding ply stress due to cyclic load; $S_{\ell}$ is the ply static strength; and $S_{\ell N A}$ is determined from Equation ( 3 ) with an appropriate safety factor. 
Displacement and buckling stress limits are checked at maximum design load (static plus cyclic) magnitude [18]. For these calculations damping and inertial effects are usually neglected.

\section{Lamination Residual Stresses}

The lamination residual stresses generally increase the transverse ply stresses. Consideration of these stresses results in thicker laminates in order to meet ply stress design requirements at combined loads. Lamination residual stresses can be determined following the procedures described in Reference 19. The lamination ply residual stresses need to be superimposed on the other ply stresses prior to checking for ply limit stresses and margins of safety.

\section{SUMMARY}

Summaries of step-by-step sample design procedures are provided for select fiber composite structures/joints including typical design results. The structures are panels subjected to combined in-plane loads and cantilever tapered box beam. The joints included are bolted and adhesively bonded types. Procedures are outlined that can be used to design for hygrothermal effects, cyclic loads and lamination residual stresses.

\section{REFERENCES}

1. B.D. Agarwal and L.J. Broutman, Analysis and Performance of Fiber Composites, John Wiley and Sons, New York, 1980.

2. 8.S. Benjamin, Structural Design With Plastics, 2nd edn., Van Nostrand Reinhold Co., New York, 1982.

3. J. Delmonte, Technology of Carbon and Graphite Fiber Composites, Van Nostrand Reinhold Co., New York, 1981.

4. R.W. Hertzberg and J.A. Manson, Fatique of Engineering Plastics, Academic Press, New York, 1980.

5. D. Hull, An Introduction to Composite Materials, Cambridge University Press, Cambridge, New York, 1981.

6. S.W. Tsai and H.T. Hahn, Introduction to Composite Materials, Technomic Publishing Co., Westport, Connecticut, 1980.

7. K.T. Kedward, Ed., Joining of Composite Materials: A Sympostum, ASTM, Philadelphia, Pennsylvania, 1981.

8. Jointing in Fiber Reinforced Plastics, IPC Science and Technology Press, Guildford, England, 1978.

9. 5. Dastin, 'Joining and machining techniques', in Handbook of Fiberglass and Advanced Plastics Composites (G. Lubin, Ed.), Von Nostrand, New York, 1969, pp. 552-591. 
10. M.W. Hyer and E.C. Klang, 'Contact stresses in pin-loaded orthotropic plates', in Int. J. Solids Struct. 21(9), 957-975 (1985).

11. C.C. Chamis, 'Design procedures for fiber composite structural components: panels subjected to combined in-plane loads', NASA TM 36909 (1985).

12. C.C. Chamis and P.L.N. Murthy, 'Design procedures for fiber composite box beams', J. Reinf. Plast. Comp. 8, 370-397 (1989).

13. C.C. Chamis, 'Simplified procedures for designing composite bolted joints', NASA TM 100281 (Feb. 1989).

14. C.C. Chamis and P.L.N. Murthy, 'Simplified procedures for designing adhesively bonded composite joints', NASA TM 102120 (Feb. 1989).

15. C.C. Chamis, R.F. Lark, and J.H. Sinclair, 'An integrated theory for predicting the hydrothermalmechanical response of advanced composite structural components', in Advanced Composite Materials: Environmental Effects (J.R. Vinson, Ed.), ASTM, Philadelphia, Pennsylvania, 1978, pp. 160-192.

16. C.C. Chamis and J.H. Sinclair, 'Prediction of composite hygral behavior made simple', SAMPE Quart. 14, 30-39 (1982).

17. C.C. Chamis and J.H. Sinclair, 'Durability/life of fiber composites in hygrothermomechanical environment', in Composite Materials: Testing and Design (I.M. Daniel, Ed.), ASTM, Philadelphia, Pennsylvania, 1982, pp. $498-512$.

18. C.C. Chamis, 'Design procedures for fiber composite structural components: rods, columns, and beam columns', Modern Plas. 60(9), 106, 108, 111 $(1983) ; 60(10), 88,90(1983) ; 60(11), 78,80(1983)$.

19. C.C. Chamis, 'Prediction of composite thermal behavior made simple', in Reinforced Plastics/Composites Institute, 36th Annual Conference Preprints, Society of the Plastics Industry, Inc., New York, 1981, pp. 1-11. 


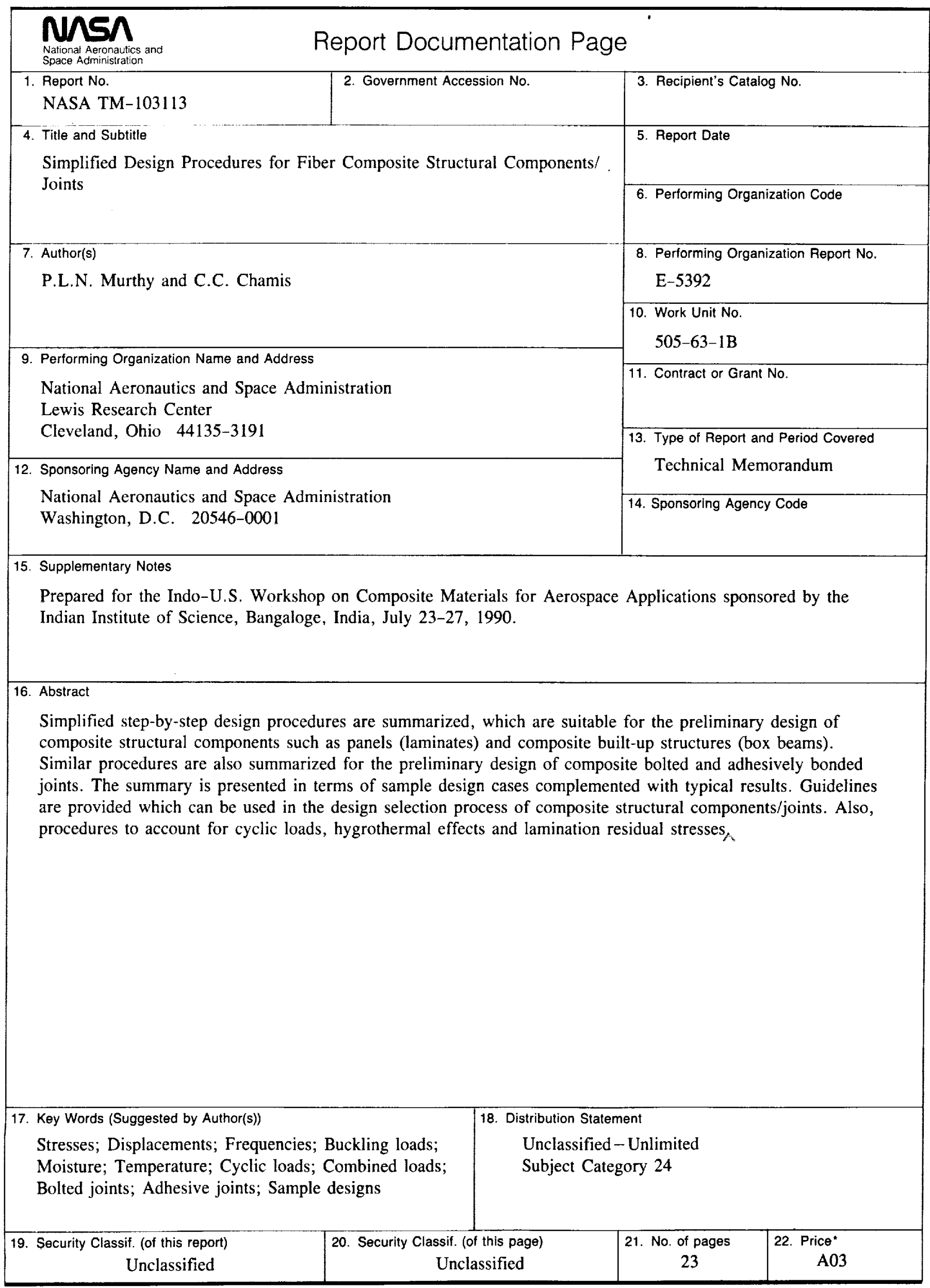

